\title{
Hegemonia e filosofia da práxis: os desafios ao Serviço Social
}

\author{
Josimeire de Omena Leite \\ Universidade Federal de Alagoas (UFAL)
}

\author{
Ana Cristina Brito Arcoverde \\ Universidade Federal de Pernambuco (UFPE)
}

\begin{abstract}
Hegemonia e filosofia da práxis: os desafios ao Serviço Social
Resumo: Este artigo trata da filosofia da práxis e dos desafios contemporâneos ao Serviço Social. Resulta de uma pesquisa teórica que, por meio de revisão bibliográfica, recupera uma importante discussão acerca de alguns conceitos gramscianos como filosofia da práxis, hegemonia e intelectual orgânico. Tem por objetivo demonstrar os novos desafios postos ao Serviço Social em tempos de neoliberalismo de terceira via, bem como revelar que o marxismo, como uma nova filosofia superior, é capaz de ordenar a nova racionalidade. Conclui que, em tempos de crise e restauração conservadora, repõem-se à profissão a exigência de uma crítica profunda em torno do avanço do pensamento pós-moderno, que difunde um modo de pensar que não ultrapassa o fenomênico e não concebe a realidade como síntese de múltiplas determinações.
\end{abstract}

Palavras-chave: Filosofia da Práxis. Hegemonia. Intelectual Orgânico. Serviço Social.

\section{Hegemony and Philosophy of Praxis: the challenges to social service}

Abstract: This article examines the philosophy of praxis and contemporary challenges to social service. It is the result of a theoretical study that conducts a bibliographic review to revive an important discussion about Gramscian concepts such as philosophy of praxis, hegemony and organic intellectual. The objective is to demonstrate the new challenges faced by social service in times of neoliberalism of the "third path", and to reveal that Marxism, as a new higher philosophy, is capable of giving order to the new rationality. It concludes that in times of crisis and conservative revival, the profession faces a demand for a profound criticism of the advance of post-modern thinking, which promotes a way of thinking that does not go beyond the phenomenon and does not conceive of reality as a synthesis of multiple determinations.

Keywords: Philosophy of praxis. Hegemony. Organic intelectual. Social Service. 


\section{Introdução}

Gramsci define bloco histórico como sendo o nexo real e indissolúvel entre estrutura, conjunto das relações materiais, e superestrutura, conjunto das relações ideológicas e culturais, e aduz que, para o seu completo funcionamento, devem ser instituídos vínculos orgânicos entre esses dois níveis imprescindíveis do real. Demonstra que a edificação e a manutenção desses vínculos são função dos intelectuais, orgânicos e tradicionais, que criam e difundem ideologias, cimentando tais vínculos, organizando e gerindo o consenso, a hegemonia e utilizando uma dosagem de coerção. É na esfera político-ideológica, ou seja, no terreno das superestruturas, que acontece em última instância a batalha decisória entre as classes sociais e que os conflitos econômicos encontram os modos de sua resolução (COUTINHO, 2011).

O conceito de hegemonia é entendido por Gramsci como direção moral e política de uma classe que detém o poder sobre os grupos afins ou aliados, ou seja, sobre todo o conjunto da sociedade. A hegemonia implica, além da ação política, a construção de uma determinada moral, de uma concepção de mundo; referese à capacidade de uma classe social unificar, em torno de seu programa político e de seu projeto de sociedade, um bloco de forças não homogêneas, abalizado por contradições no interior da própria classe.

$\mathrm{O}$ texto que segue vem demonstrar que a retomada das reflexões gramscianas em torno dos conceitos de filosofia da práxis e da relação entre hegemonia e intelectual orgânico é relevante, não só para a análise da crise e recomposição do bloco histórico neoliberal a partir da década de 1990, mas também para se contrapor às ideologias reacionárias, em tempos de neoliberalismo de terceira via, nos quais os ideólogos da classe dominante afirmam, repetidamente, a morte da filosofia da práxis, numa incansável tentativa de descaracterizála, esterilizá-la ou neutralizá-la.

\section{Hegemonia e a filosofia da práxis}

Para Gramsci (2006, p. 103), só a filosofia da práxis é capaz de unificar e elevar as pessoas simples ao nível de uma visão superior:

A filosofia da práxis não busca manter os 'simples' na sua filosofia primitiva do senso comum, mas busca, ao contrário, conduzi-los a uma concepção de vida superior. Se ela afirma a exigência do contato entre os intelectuais e os simples não é para limitar a atividade científica e para manter uma unidade no nível inferior das massas, mas justamente para forjar um bloco intelectual-moral que torne politicamente possível um progresso intelectual de massa e não apenas de pequenos grupos intelectuais.

Dias (1996, p. 56) enfatiza que a filosofia da práxis é uma teoria revolucionária, é uma teoria superior devido à sua capacidade de ordenar a nova racionalidade: "revolucionária e autônoma porque, contrariamente às demais filosofias e concepções de mundo, ela pretende "tornar os governados intelectualmente independentes dos governantes, para destruir uma hegemonia e construir outra", ou seja, uma nova hegemonia.

Para Gramsci (2006, p. 320), a realização de um aparelho hegemônico, enquanto cria um novo terreno ideológico, determina uma reforma das consciências e dos métodos de conhecimento, "é um fato de conhecimento, um fato filosófico". A filosofia da práxis é eficaz como projeto hegemônico, crítico das outras visões de mundo, e por essa razão torna-se alvo de várias críticas. No entanto, acredita que a crítica real de uma concepção de mundo requer o embate hegemônico, a luta entre modos de ver a realidade:

que significação tem o fato de que uma concepção do mundo, que se enraíza e se difunde desta maneira tenha continuamente momentos de renovação e de novo esplendor intelectual? É um preconceito de intelectuais fossilizados acreditar que uma concepção do mundo possa ser destruída por críticas de caráter racional. Quantas vezes não se falou de 'crise' da filosofia da práxis? E que significa esta crise permanente? Não significará, por acaso, a própria vida, que procede através de negações? Ora, quem conservou a força das sucessivas retomadas teóricas, se não a fidelidade das massas populares que se apropriaram da concepção, ainda que sob formas supersticiosas e primitivas? [...] Não se observa que precisamente a difusão da filosofia da práxis é a grande reforma dos tempos modernos, é uma reforma intelectual e moral que realiza em escala nacional o que o liberalismo conseguiu realizar apenas em pequenos estratos da população (GRAMSCI, 2006, p. 362).

Dias (1996, p. 46) entende que o marxismo é essa nova visão de mundo, essa nova filosofia superior, que "vê o processo economia/política como construção ativa dos homens, e afirma a estrutura como a articulação 
específica das classes, de suas práticas e confrontos", portanto, uma filosofia capaz de ordenar a nova racionalidade. Este autor observa:

A melhor demonstração da necessidade de se liquidar a concepção adversária é dada pela afirmação das repetidas mortes da filosofia da práxis, registradas nos cartórios da luta política e das ideologias reacionárias [...] A filosofia da práxis é eficaz porque concebe a realidade das relações humanas de conhecimento como elemento de 'hegemonia política'. [...] Essa sua eficácia como projeto hegemônico, crítico das outras visões de mundo, faz com que ela própria seja criticada, processo que é uma tentativa de transformá-la, obtendo assim sua descaracterização, esterilização ou neutralização (DIAS, 1996, p. 20).

Gramsci (2002a, p. 34) também entendia o exercício normal da hegemonia como uma combinação da força e do consenso, mesmo nos regimes políticos nos quais predominavam as formas democrático-liberais. Em seus escritos é célebre a imagem do centauro que ele utiliza para destacar a unidade orgânica entre coerção e consenso, da relação dialética entre essas duas naturezas do poder político, em que a coerção não pode existir sem o consenso e vice-versa:

Outro ponto a ser fixado e desenvolvido é o da 'dupla perspectiva' na ação política e na vida estatal [...] que pode ser reduzido teoricamente a dois graus fundamentais, correspondentes à natureza dúplice do Centauro maquiavélico, ferina e humana, da força e do consenso, da autoridade e da hegemonia, da violência e da civilidade [...] da agitação e da propaganda [...] Alguns reduziram a teoria da "dupla perspectiva" a algo mesquinho e banal, ou seja, a nada mais que duas formas de 'imediaticidade' que se sucedem mecanicamente no tempo, com maior ou menor 'proximidade'.

No Caderno 12, § 1, Gramsci (2004, p. 20) entende a sociedade civil como "o conjunto de organismos vulgarmente chamados privados", destacando, no caderno $6, \S 136$, o seu caráter material - a materialidade dos processos de conformação de uma hegemonia - através da expressão "aparelho hegemônico de um grupo social" (2002a, p. 253) e, no § 137, com a expressão "aparelho privado de hegemonia" (2002a, p. 255). Numerosas são as instituições, os aparelhos hegemônicos, que constituem a sociedade civil: universidades, escolas, igrejas e associações privadas, os círculos e os clubes de variados tipos, sindicatos, partidos, imprensa, entre outras.

Segundo Bianchi (2008, p. 179), a luta de hegemonias não se limita apenas à luta entre concepções de mundo, mas também é luta dos aparelhos que se configuram como suportes materiais dessas ideologias, visto que as organizam e as difundem: “a função desses organismos é articular o consenso das grandes massas e sua adesão à orientação social impressa pelos grupos dominantes. Esse conjunto de organismos, entretanto, não é socialmente indiferenciado. Os cortes classistas e as lutas entre os diferentes grupos sociais atravessam os aparelhos hegemônicos e contrapõem uns aos outros". O próprio conceito de hegemonia, aprofundado por Gramsci, permite afirmar que será pela disputa pela direção da sociedade e, consequentemente, pelos aparelhos privados de hegemonia, que as classes sociais terão suas chances de convencer a sociedade como um todo quanto à validade de seus interesses particulares. Neves (2005, p. 24) observa que a politização da sociedade civil também:

propiciou à burguesia um novo conteúdo e uma nova forma às suas estratégias de dominação, transformando-a simultaneamente, de modo mais equilibrado, em classe dominante e classe dirigente [...] Mais ainda, a politização da sociedade civil demanda um novo formato às disputas pelo próprio poder, uma vez que a balança entre coerção e consenso ou repressão e convencimento terá de ser direcionada pela busca incessante de legitimação de um conjunto de práticas e ideias destinadas à tentativa de conversão de interesses particulares em gerais, a qual, se dotada de êxito, irá colaborar para que a classe burguesa consiga resolver a seu favor a possível (e sempre presente) contradição entre domínio e direção, tornando esses termos complementares e, para a sociedade, não conflitantes.

É possível identificar a relação domínio/direção nos escritos de Gramsci (2002b, p. 63), precisamente quando ele trata da relação hegemonia/supremacia. A supremacia de um grupo se manifesta de como domínio e como direção intelectual e moral:

Um grupo social domina os grupos adversários, que visa a 'liquidar' ou a submeter, inclusive com a força armada, e dirige os grupos afins e aliados. Um grupo social pode e, aliás, deve ser dirigente já antes de conquistar o poder governamental (esta é uma das condições principais para a própria conquista do poder); depois, quando exerce o poder, e mesmo se o mantém fortemente nas mãos, torna-se dominante, mas deve 
continuar a ser também 'dirigente'. Os moderados continuaram a dirigir o Partido de Ação mesmo depois de 1870 e 1876, e o chamado ‘transformismo' foi somente a expressão parlamentar desta ação hegemônica, moral e política.

Gramsci chega a esta percepção quando analisa o problema da direção política na formação e no desenvolvimento da nação e do Estado moderno na Itália. É marcante a relação entre a conquista do poder pela burguesia e o surgimento do mundo moderno. Como observa Bianchi (2008), a revolução passiva, como cânone de interpretação histórica, tornou-se uma chave teórica para o entendimento do surgimento da modernidade capitalista na maioria dos países europeus. Ao discutir o conceito de revolução passiva, Gramsci tematiza as formas de passivização, desencadeada pelas classes dominantes, de processos revolucionários do tipo jacobino e bolchevique. Nesta tematização, fica também explícito que a essencial tarefa histórica do capitalismo seria, através das modificações das formas de organização da vida estatal, abolir toda e qualquer iniciativa hegemônica por parte das classes subalternas visando superar as relações de produção dominantes.

\section{A relação entre hegemonia e intelectual orgânico}

Coutinho (2011, p. 30) frisa que a centralidade da luta pela hegemonia na nova estratégia revolucionária sugerida por Gramsci elucida a razão por que o estudo da função e do papel social dos intelectuais tem um peso tão decisivo nos Cadernos do Cárcere. Para Gramsci, os intelectuais são sujeitos fundamentais das batalhas hegemônicas:

são intelectuais (ou desempenham uma função intelectual) todos os membros de um partido político, de um sindicato, de uma organização social. Ele distingue, por um lado, entre o 'grande intelectual', aquele que cria novas concepções do mundo, e a massa dos demais intelectuais, que difundem tais concepções; e, por outro, faz também uma decisiva distinção entre 'intelectuais orgânicos', que são gerados diretamente por uma classe e servem para lhe dar consciência e promover sua hegemonia, e 'intelectuais tradicionais', que se vinculam a instituições que o capitalismo herda de formações sociais anteriores (como as Igrejas e o sistema escolar) [...] Tarefa de uma classe que busca hegemonia é não apenas criar seus próprios intelectuais 'orgânicos', mas também assimilar aqueles 'tradicionais'.

Para uma melhor compreensão da função e do papel social dos intelectuais, enquanto sujeitos fundamentais das batalhas hegemônicas, é necessária uma abordagem, mesmo que em linhas gerais, do conceito gramsciano de intelectual orgânico. Gramsci (2004, p. 18-19) afirma que todos os homens são intelectuais ${ }^{1}$, mas também entende que nem todos têm na sociedade a função de intelectuais. Historicamente, são formadas "categorias especializadas para o exercício da função intelectual; formam-se em conexão com todos os grupos sociais mas, sobretudo, em conexão com todos os grupos sociais mais importantes e sofrem elaborações mais amplas e complexas em ligação com o grupo social dominante". São os intelectuais orgânicos, pois nascem no seio de cada grupo social:

Todo grupo social, nascendo no terreno originário de uma função essencial no mundo da produção econômica, cria para si, ao mesmo tempo, organicamente, uma ou mais camadas de intelectuais que lhe dão homogeneidade e consciência da própria função, não apenas no campo econômico, mas também no social e político: o empresário capitalista cria consigo o técnico da indústria, o cientista da economia política, o organizador de uma nova cultura, de um novo direito, etc. (Gramsci, 2004, p. 15).

Vê-se, portanto, que de uma atividade ligada à produção econômica, a classe social que ambiciona a direção/dominação da sociedade cria intelectuais especializados para as funções diretivas e burocráticas cujo fim é a defesa dos seus interesses.

Outro enfoque de Gramsci (2004, p. 20) refere-se à relação entre os intelectuais e o mundo da produção, relação não imediata, como acontece no caso dos grupos sociais fundamentais, "mas é 'mediatizada', em diversos graus, por todo o tecido social, pelo conjunto das superestruturas, do qual os intelectuais são precisamente os "funcionários"'. Assim, a partir de uma atividade técnica de produção, tais intelectuais especializamse em outras áreas, todas ligadas a superestruturas, justificando ideologicamente o crescimento econômicosocial do grupo ao qual estão vinculados.

Ao tratar sobre a função de hegemonia e a de domínio direto que o grupo dominante exerce em toda a sociedade, Gramsci $(2004$, p. 21$)$ demonstra que tais funções são organizativas, conectivas e exercidas por seus intelectuais: 
Os intelectuais são os 'prepostos' do grupo dominante para o exercício das funções subalternas da hegemonia social e do governo político, isto é: 1) do consenso 'espontâneo' dado pelas grandes massas da população à orientação impressa pelo grupo fundamental dominante à vida social, consenso que nasce 'historicamente' do prestígio (e, portanto, da confiança) obtido pelo grupo dominante por causa de sua posição e de sua função no mundo da produção; 2) do aparelho de coerção estatal que assegura 'legalmente' a disciplina dos grupos que não 'consentem', nem ativa nem passivamente, mas que é constituído para toda a sociedade na previsão dos momentos de crise no comando e na direção, nos quais desaparece o consenso espontâneo.

No bloco histórico, a classe dominante cumpre, em relação aos grupos subalternos, uma dupla função: hegemônica e coercitiva, e esta se dá de modo mediato. Assim, pois, tal mediação é a função fulcral dos intelectuais orgânicos, enquanto funcionários das superestruturas, intermediários do grupo dominante para o exercício das funções subalternas de hegemonia social e do governo político. Um tipo de intelectual não mais unido diretamente à produção econômica, mas às superestruturas, embora não perde seu vínculo orgânico com a classe à qual se vincula e ela é determinada pelo lugar na produção. Staccone (1982, p. 31) entende que a estabilidade do bloco histórico depende diretamente da organização e da eficiência dos órgãos da sociedade civil sob o comando dos intelectuais orgânicos dos grupos dominantes. "Daí a grande importância atribuída aos intelectuais, pois como 'funcionários' daqueles órgãos jogam um papel essencial na conservação do bloco existente, como também na provocação da crise que possibilita a formação de um novo bloco". Entretanto, "o intelectual orgânico não é o reflexo passivo de uma classe social, pois goza de uma relativa autonomia por ser funcionário das superestruturas".

Gramsci (2004) deixou claro que o capitalismo, como prática material e estatal, ampliou o número de intelectuais e padronizou-os, justificando suas funções não apenas pelas necessidades sociais da produção, mas também pelas necessidades políticas do grupo fundamental dominante. Como observa Dias (1996), Gramsci antecipou toda uma problemática da relação intelectuais/mundo da produção/dominação de classe. Ao problematizar tal relação, Gramsci entendia que os grupos dominados eram tais porque lhes faltava a unidade entre a ação e a teoria. Fadados à execução de tarefas mecânicas e técnicas, tais grupos não puderam elaborar criticamente uma filosofia correspondente ao seu estágio de participação no trabalho e ao seu peso no equilíbrio de forças dentro da sociedade:

Põe-se, portanto, o problema da criação de uma nova camada de intelectuais orgânicos a esta classe social, capaz de elaborar uma nova filosofia, com base na atividade prática deles; isto é, enquanto o trabalho inova continuamente o mundo físico e social, torna-se fundamento de uma nova e integral concepção do mundo. Trata-se de explicitar aquela filosofia que está implícita na ação prática de cada um, e dos grupos sociais. É este o desafio para os intelectuais dos grupos subalternos (STACCONE, 1982, p. 33).

Gramsci (2004, p. 53) enfatiza que "o modo de ser do novo intelectual não pode mais consistir na eloquência [...] mas numa inserção ativa na vida prática, como construtor, organizador, "persuasor permanente", cujo fim é a construção de uma nova hegemonia e de uma nova sociedade. Vale ainda ressaltar que Gramsci (2006, p. 221), ao discorrer sobre a relação intelectual/povo, afirma que "o elemento popular 'sente', mas nem sempre compreende, ou sabe; o elemento intelectual 'sabe', mas nem sempre compreende e, menos ainda, "sente"". Portanto, trata-se de criar uma "unidade orgânica entre teoria e prática, entre camadas intelectuais e massas populares" (GRAMSCI, 2002a, p. 92), uma relação dialética que possibilita o crescimento e a elevação cultural de ambos e o afirmar-se de uma nova hegemonia.

\section{O Social-liberalismo internacional: uma nova estratégia de legitimação do consenso em torno da atual sociabilidade burguesa}

Sobre a centralidade do conceito de hegemonia no pensamento gramsciano, Castelo (2011, p. 3940) aponta a existência de uma acirrada batalha quanto ao seu significado: "os comentadores dos escritos do comunista sardo trazem sentidos múltiplos para o conceito, sendo alguns deles uma forma de neutralizar a radicalidade das proposições teóricas e políticas de Gramsci”. Dias (1996, 1996, p. 10) também identifica a existência de uma literatura que se autodenomina gramsciana, mas que, na realidade, pensa a hegemonia instrumentalmente. Boa parte dessa literatura trabalha de forma abstrata a hegemonia, considerando-a como a capacidade de uma classe de subordinar, de coordenar classes aliadas ou inimigas, ou simplesmente como efeito de uma determinação mecânica do econômico ou, até mesmo, como mera obtenção de um domínio ideológico: 
Para nós, diferentemente, a questão central é o nexo entre a capacidade de construção de uma visão de mundo (Weltanschauung) e realização da hegemonia. A capacidade que uma classe fundamental (subalterna ou dominante) tem de construir sua hegemonia decorre da sua possibilidade de elaborar sua visão de mundo própria, autônoma. Esse processo de 'construção da hegemonia', que ocorre no cotidiano antagônico das classes, decorre da sua capacidade de elaborar sua visão de mundo autônoma e da centralidade das classes. Essa centralidade, tomada como 'síntese de múltiplas determinações', e não como um a priori lógico, como um 'efeito da estrutura', é determinante no exercício da hegemonia.

Em Gramsci, o nível da sociedade civil condiz com a função de hegemonia que o grupo dirigente exerce em toda a sociedade. O conceito de hegemonia compreende a função de direção intelectual e moral, e de dominação, praticada por uma classe social sobre as demais classes, através dos órgãos da sociedade civil e política. Dias (1996, p. 52) constata que o processo de hegemonia supõe, antes de tudo, a autonomia da construção da visão de mundo: "Autonomia e/ou subordinação são faces dessa luta de hegemonias, que nada mais é do que o cotidiano das classes e de suas lutas". Nessa mesma direção, Neves (2005, p. 24) observa que a politização da sociedade civil:

contribui para que o consenso ou adesão espontânea de indivíduos ou grupos aos projetos das classes sociais em disputa na sociedade civil (e também no Estado em sentido estrito) passe a se constituir, ao mesmo tempo, em importante instrumento de dominação da classe burguesa para a consolidação de sua hegemonia nas sociedades contemporâneas, e em poderoso meio de emancipação política das classes dominadas na construção de uma outra hegemonia: a direção intelectual e moral, política e cultural da classe trabalhadora.

Castelo (2011) observa que, para obter êxito na reafirmação da sua supremacia, as classes dominantes utilizaram não apenas os recursos hegemônicos e consensuais, mas, nas situações mais extremas, também recorreram aos recursos de dominação-coerção, como forte repressão policial, criminalização da pobreza, e as invasões militares na periferia do mercado mundial. A queda do Muro de Berlim e o colapso do socialismo real no Leste Europeu foram duros golpes que coroaram a supremacia neoliberal no Velho Continente, ocorrendo uma cooptação massiva de antigos dirigentes social-democratas e comunistas em toda a Europa, que passaram a operacionalizar as políticas neoliberais:

Se, até então, o neoliberalismo era efetivado segundo a agenda política dos partidos conservadores, no final de 1980 e início dos 1990, os partidos de esquerda não somente aderiram ao ideário neoliberal como o concretizaram nas suas ações de governo, muitas vezes aprofundando o programa político dos rentistas, pois a adesão maciça da social-democracia e dos ex-comunistas desarmou as bases sociais que poderiam se opor à supremacia burguesia. Sem maiores resistências dos seus potenciais adversários, o projeto neoliberal viu-se livre de amarras e tratou de expandir mundialmente a sua supremacia, atingindo as regiões subdesenvolvidas e periféricas a partir de meados dos anos 1980 e particularmente com força em 1990, tendo como base o Consenso de Washington (CASTELO, 2011, p. 238).

Ao refletir criticamente sobre os elementos da crise conjuntural do bloco histórico neoliberal nos anos 1990, e sobre a resposta social-liberal, Castelo (2011, p. 246-7) ressalta problemas como a estagnação das taxas de crescimento econômico, o crescimento do desemprego e o aumento dos índices de pobreza e desigualdade social decorrentes dos planos de ajuste estrutural que foram efetuados de acordo com a correlação de forças de cada país: "gradativamente tomou-se consciência de que o receituário-ideal do neoliberalismo não reunia condições políticas e ideológicas para cumprir suas (falsas) promessas [...] Seria preciso remover tais barreiras e promover um aprofundamento das medidas liberalizantes". Para os ideólogos do social-liberalismo, a ênfase deveria ser dada aos mecanismos de mercado na produção da riqueza e, concomitantemente, se passaria a reconhecer as falhas de mercado no tocante à distribuição de renda (CASTELO, 2011).

Assim, a ofensiva rentista ajustou sua estratégia inicial de restauração para uma reforma-restauradora a partir da última década do século 20, visando à conservação do bloco histórico neoliberal (CASTELO, 2011). A Terceira Via configurou-se como um vigoroso programa político voltado a orientar a chamada política radical de centro, que cada vez mais vem obtendo o apoio de partidos, de governos de vários países e de organizações da sociedade civil vinculadas ao campo empresarial.

Voltando o olhar para os escritos de Anthony Giddens, Martins (2009, p. 66) identifica que a Terceira Via tem como ponto de partida a premissa de que as forças sociais anticapitalistas foram sepultadas nos escombros do Muro de Berlim. Com tal assertiva, Giddens decreta a "inviabilidade histórica” do socialismo revolucionário 
sob a alegação de que a esquerda clássica passa a inexistir, que "a esquerda se resumiu à velha socialdemocracia e a direita se converteu ao neoliberalismo, e ambas se demonstram incapazes de apontar 'saídas' políticas e econômicas de sucesso". Observa ainda que, na defesa das posições dos novos democratas e do novo trabalhismo, acusados de deslocar seus partidos para a direita, Giddens afirma que eles começaram a se adaptar às mudanças que limitam a relevância das velhas ideologias. Os escritos de autores da tradição marxista, revelam que para o social-liberalismo (brasileiro e internacional) ou neoliberalismo de terceira via, era possível pensar em relações capitalistas mais harmônicas. Assim, numa crítica acrítica ao Consenso de Washington (CASTELO, 2011; MOTTA, 2012), seus ideólogos advogavam que as lutas de classes gradativamente recuariam, dando lugar a uma concertação social. Os ideólogos do social-liberalismo entendiam que os problemas sociais provocados pelo neoliberalismo foram bastante negativos por terem motivado revoltas sociais contra o neoliberalismo e a globalização que abalaram a coesão social, pois todas as perspectivas de crescimento diante do desenvolvimento tecnológico, das possibilidades produtivas e comerciais, e do mercado livre e global, naufragaram num fosso de pobreza e desigualdades entre classes e em regiões inteiras. Assim, diante das sublevações elementares das massas, os grupos dirigentes responderam com um reformismo temperado (KANOUSI; MENA, 1985).

Em síntese, o pensamento do social-liberalismo internacional defendia: uma terceira via entre o mercado e o socialismo (GIDDENS, 2001); políticas pró-competição, políticas facilitadoras de transferência de tecnologia e transparência nas informações, governo e mercado (complementaridade), educação e equidade e a humanização da globalização (STIGLITZ, 1998; 2003; 2007); a implantação de reformas de segunda geração

(política anticíclica, reforma financeira, reformas ins-

...a filosofia da práxis é eficaz

como projeto hegemônico e

crítico das outras visões de

mundo e, por esse motivo,

torna-se alvo de diversas

críticas. titucionais, distribuição de renda), a privatização e a capacitação dos pobres via educação (WILLIAMSON, 2003); defendia o estímulo ao pleno desenvolvimento dos mercados com a criação de instituições sólidas criadoras de mercado, reguladoras do mercado para lidar com externalidades (desigualdades sociais, pobreza), estabilizadoras do mercado e legitimadoras do mercado (RODRIK, 2002). Também advogava que a ação do governo deveria proteger os grupos vulneráveis (BANCO MUNDIAL, 1997) e, adotando um discurso pró-pobre, propugnava a expansão da educação colocando-a como promotora de uma maior igualdade de oportunidade e mobilidade social (IETS, 2001).

Assim, diante dos erros e falhas do Consenso de Washington, esses ideólogos defendiam um Estado forte e convidavam as lideranças de todos os segmentos sociais para que abdicassem de representar os interesses particulares das suas bases sociais a favor da vontade geral da nação, não considerando que a sociedade era atravessada por desigualdades, contradições e antagonismo de classes (CASTELO, 2011). Esse programa político concebia o diálogo como a tentativa de conciliação dos inconciliáveis interesses entre capital e trabalho, para a obtenção de um consentimento ativo dos trabalhadores, obscurecendo o aprofundamento dos antagonismos sociais que caracterizam a atual fase do capitalismo. A Terceira Via, como projeto de socialliberalismo, é uma conceituação que expressa de forma clara a retomada envernizada do projeto burguês, conservando-se as premissas básicas do neoliberalismo e associando-as aos elementos centrais do reformismo socialdemocrata $^{2}$ (CASTELO, 2011; LIMA; MARTINS, 2005).

É alicerçado nesse entendimento que se torna possível identificar a problemática central do socialliberalismo que é preservar, prioritariamente, a lógica do mercado combinada com um nível de regulação estatal, para que seja evitado o agravamento de certas expressões da questão social bem como as revoltas populares. Para Castelo (2011, p. 259), o social-liberalismo "é uma expressão teórica adequada aos interesses materiais da burguesia rentista, pois, ao mesmo tempo em que defende a acumulação capitalista na sua face financeirizada, propõe soluções para seus efeitos mais deletérios, tendo em vista a coesão social e a manutenção da ordem burguesa".

Seja na defesa de um capitalismo responsável, capitalismo humanizado ou de uma globalização com face humana, os intelectuais orgânicos da chamada Terceira Via apresentam suas propostas como algo novo ao neoliberalismo e à antiga socialdemocracia. Na realidade, esse ramo do social-liberalismo intenciona preservar a primazia da lógica do mercado, mantendo os princípios básicos do neoliberalismo com algumas nuances e criando um novo consenso em torno da sociabilidade burguesa. 


\section{Desafios contemporâneos ao Serviço Social em tempos de neoliberalismo de terceira via}

O Serviço Social deve ser considerado como "atividade socialmente determinada pelas circunstâncias sociais objetivas que imprimem certa direção social ao exercício profissional, que independem de sua vontade e/ou da consciência de seus agentes individuais" (YAZBEK, 2009, p. 4). Assim, em tempos de crise e restauração conservadora, de neoliberalismo de terceira via, novos desafios são postos ao Serviço Social, tanto na formação como no exercício profissional, pois se põe, cada vez mais, a exigência de uma crítica profunda em torno do avanço do pensamento pós-moderno e do espraiar-se de uma cultura irracionalista do imediato que, por sua vez, dissemina um modo de pensar que não ultrapassa o fenomênico e não concebe a realidade como síntese de múltiplas determinações instigando, assim, à mera reposição do sincretismo profissional. Em tempos de crise e reestruturação produtiva do capital, onde o capitalismo vai se reinventando em suas formas, são postos à formação um duplo desafio: "desvelar e enfrentar a crise do capital e nela, as diversas formas de precarização das relações e condições de trabalho, flexibilização dos direitos e focalização das políticas sociais que, como parte da mesma racionalidade, se expressam e condicionam exercício e formação profissionais" (GUERRA, 2010, p. 715). Nesse novo cenário, torna-se fundamental "apreender as implicações políticas do exercício profissional que se desenvolve no contexto de relações entre classes [...] não podendo ser pensada fora dessa trama" (YAZBEK, 2009, p. 4). Nessa direção, Leite (2012) chama a atenção para o fato de que, para fazer frente ao novo projeto de restauração da ordem do capital, a atuação profissional deve pautar-se pela busca do fortalecimento da prática político-organizativa da categoria e pela luta visando à manutenção da autonomia de suas organizações. Diante da ofensiva do capital no seu ímpeto restaurador, "apenas mediante uma profunda interlocução da categoria profissional com o marxismo é que se põe concretamente a possibilidade de um olhar crítico sobre o Serviço Social e a apropriação das ferramentas necessárias ao enfrentamento dos novos desafios à consolidação de uma cultura crítica no interior da profissão e ao processo de manutenção da hegemonia do seu projeto ético-político" (LEITE, 2012, p. 133).

Por fim, vale ressaltar a relevância do trabalho do assistente social enquanto intelectual orgânico da classe trabalhadora. Estudos de Iamamoto, Carvalho e Conceição (2010, p. 56) ressaltam que "a função educativa dos assistentes sociais integra o amplo processo de elaboração de uma ideologia própria, desenvolvida por essa classe, como elemento constitutivo de uma nova e superior cultura". E tal função ainda "supõe compromisso político consciente com o projeto societário das classes subalternas e competências teóricometodológicas e políticas para a identificação e apropriação das reais possibilidades postas pelo movimento social para o redimensionamento da prática profissional no horizonte da luta pela emancipação das referidas classes" (CONCEIÇÃO, 2010, p. 56).

Para Gramsci (2004, p. 53), "o modo de ser do novo intelectual não pode mais consistir na eloquência [...] mas numa inserção ativa na vida prática, como construtor, organizador, "persuasor permanente"”, cujo fim é a construção de uma nova hegemonia e de uma nova sociedade. Portanto, é reconhecida a contribuição do Serviço Social, enquanto profissão e área de produção de conhecimento, na criação de consensos na sociedade em torno de interesses das classes fundamentais, tanto no sentido de reforçar a hegemonia vigente, quanto em criar uma nova hegemonia.

\section{Conclusão}

Este estudo elucida uma importante contribuição do pensamento de Gramsci que é o revelar do marxismo como uma nova filosofia superior capaz de ordenar a nova racionalidade. Demonstra que a filosofia da práxis é eficaz como projeto hegemônico e crítico das outras visões de mundo e, por esse motivo, torna-se alvo de diversas críticas. Revela que a capacidade que uma classe fundamental, subalterna ou dominante, tem de construir sua hegemonia, deriva da sua possibilidade de elaborar sua visão de mundo própria, autônoma e, ao tratar sobre a função de hegemonia e a de domínio direto que o grupo dominante exerce em toda a sociedade, esclarece que tais funções são organizativas e exercidas por seus intelectuais.

Este estudo, ao refletir criticamente sobre a crise conjuntural do bloco histórico neoliberal e sobre a resposta social-liberal, indica que, em tempos de neoliberalismo de terceira via, novos desafios são postos ao serviço social, tanto na formação como no exercício profissional, colocando-se, cada vez mais, a exigência de uma crítica profunda em torno do avanço do pensamento pós-moderno e do espraiar-se de uma cultura irracionalista do imediato que difunde um modo de pensar que não ultrapassa o fenomênico e não concebe a realidade como síntese de múltiplas determinações incitando, portanto, à mera reposição do sincretismo profissional. 


\section{Referências:}

BANCO MUNDIAL. Relatório sobre o desenvolvimento mundial 1997: o estado num mundo em transformação. Washington: Oxford University Press, 1997.

BIANCHI, Á. O laboratório de Gramsci: filosofia, história e política. São Paulo: Alameda, 2008.

CASTELO, R. O social-liberalismo: uma ideologia neoliberal para a "questão social” no século XXI. 2011. 380 f. Tese (Doutorado em Serviço Social) - Universidade Federal do Rio de Janeiro, Rio de Janeiro, 2011.

COUTINHO, C. N. Introdução. In: COUTINHO, C. N. (Org.). O leitor de Gramsci: escritos escolhidos 1916-1935. Rio de Janeiro: Civilização Brasileira, 2011.

CONCEIÇÃO, D. G. da. O serviço social e prática pedagógica: a arte como instrumento de intervenção social. Serviço Social em Revista, Londrina, v. 12, n. 2, p. 51-67, jan./jun. 2010. Disponível em: http://www.uel.br/revistas/uel/index.php/ssrevista/article/view/7542/ 6830. Acesso em: 10 set. 2016.

DIAS, E. F. et al. O outro Gramsci. São Paulo: Xamã, 1996.

GIDDENS, A. A terceira via e seus críticos. Tradução de Rita Vinagre. Rio de Janeiro: Record, 2001.

GUERRA, I. A formação profissional frente aos desafios da intervenção e das atuais configurações do ensino público, privado e a distância. Serviço Social \& Sociedade, São Paulo, n. 104, p. 715-736, out./dez. 2010.

INSTITUTO DE ESTUDOS DO TRABALHO E SOCIEDADE. Desenvolvimento com justiça social: esboço de uma agenda integrada para o Brasil. Rio de Janeiro, 2001. (Policy Paper, 1). Disponível em: http://www.senado.leg.br/comissoes/cas/ds/IETSDesenv.pdf. Acesso em: 23 jun. 2016.

GRAMSCI, A. Cadernos do Cárcere. Tradução de Carlos Nelson Coutinho, Luiz Sérgio Henriques e Marco Aurélio Nogueira. Rio de Janeiro: Civilização Brasileira, 2006. v. 1.

. Tradução de Carlos Nelson Coutinho, Luiz Sérgio Henriques e Marco Aurélio Nogueira. Rio de Janeiro: Civilização Brasileira, 2004. v. 2.

. Tradução de Carlos Nelson Coutinho, Luiz Sérgio Henriques e Marco Aurélio Nogueira. Rio de Janeiro: Civilização Brasileira, 2002a. v. 3.

. Tradução de Carlos Nelson Coutinho, Luiz Sérgio Henriques e Marco Aurélio Nogueira. Rio de Janeiro: Civilização Brasileira, 2002b. v. 5.

KANOUSSI, D.; MENA, J. La revolución pasiva: una lectura a los cuadernos de la Cárcel. México: Universidad Autónoma de Puebla, 1985. LEITE, J. de O. Cultura crítica e o projeto ético-político do serviço social brasileiro: desafios contemporâneos. Em Pauta, Rio de Janeiro, n. 29, v. 10, p. 119-136, 2012.

LIMA, K. R. de S.; MARTINS, A. S. A nova pedagogia da hegemonia, pressupostos, princípios e estratégias. In: NEVES, L. M. W. (Org.). A nova pedagogia da hegemonia: estratégia do capital para educar o consenso. São Paulo: Xamã, 2005. p. 43-68.

MARTINS, A. S. A direita para o social: a educação da sociabilidade no Brasil contemporâneo. Juiz de Fora: EdUFJF, 2009.

MOTTA, V. C. da. Ideologia do capital social: atribuindo uma face mais humana ao capital. Rio de Janeiro: UERJ, 2012.

NEVES, L. (Org.). A nova pedagogia da hegemonia: estratégias do capital para educar o consenso. São Paulo: Xamã, 2005.

RODRIK, D. Depois do neoliberalismo, o quê? In: CASTRO, A. C. (Org.). Desenvolvimento em debate: novos rumos do desenvolvimento no mundo. Rio de Janeiro: Mauad: BNDES, 2002. p. 277-298. v. 1. Disponível em: http://www.bndes.gov.br/SiteBNDES/export/sites/ default/bndes_pt/Galerias/Arquivos/conhecimento/livro_debate/1-DesenvGlob.pdf. Acesso em: 10 jul. 2016.

STACCONE, G. Bloco histórico e hegemonia. Recife: Centro Pastoral Vergueiro, 1982.

STIGLITZ, J. E. A globalização e seus malefícios: a promessa não cumprida de benefícios globais. Tradução de Bazán Tecnologia e Lingüística. São Paulo: Futura, 2003.

Globalização: como dar certo. Tradução de Pedro Maia Soares. São Paulo: Companhia das Letras, 2007.

. Neoliberalismo em choque: o pós-consenso de Washington. Folha de São Paulo, São Paulo, 12 jul. 1998. Disponível em: http:/ /webcache.googleusercontent.com/search?q=cache:4U5Lfdw9JIUJ:www1.folha.uol.com.br/fsp/mais/fs12079804.htm+\&cd=1\&hl=ptBR\&ct=clnk\&gl=br. Acesso em: 03 jul. 2016.

WILliAMSON, J. Depois do consenso de Washington: uma agenda para reforma econômica na América Latina. São Paulo, 2003. Disponível em: http://www.iie.com/publications/papers/williamson0803.pdf. Acesso em: 05 jul. 2016.

YAZBEK, M. C. O significado sócio-histórico da profissão. In: CONSELHO FEDERAL DE SERVIÇO SOCIAL; ASSOCIAÇÃO BRASILEIRA DE ENSINO E PESQUISA EM SERVIÇO SOCIAL (Org.). Serviço social: direitos sociais e competências profissionais. Brasília, DF: CFESS: ABEPSS, 2009. p. 125-141.

\section{Notas}

1 Segundo Gramsci (2004, p. 53), “todo homem, fora de sua profissão, desenvolve uma atividade intelectual qualquer, ou seja, é um 'filósofo', um artista [...] participa de uma concepção do mundo, possui uma linha consciente de conduta moral, contribui assim para manter ou para modificar uma concepção do mundo, isto é, para suscitar novas maneiras de pensar". 
2 Castelo (2011, p. 272) elucida que "as teorias do social-liberalismo é um projeto ideológico classista de retomada da supremacia neoliberal que ganhou impulso com o acoplamento de amplos setores da socialdemocracia e mesmo do comunismo ao novo reformismo-restaurador liberal".

\section{Josimeire de Omena Leite}

Universidade Federal de Alagoas (UFAL)

Assistente Social, mestra e doutora em serviço social pela Universidade Federal de Pernambuco (UFPE), professora adjunta da Universidade Federal de Alagoas.

Faculdade de Serviço Social - UFAL. Campus A. C. Simões. Av. Lourival Melo Mota, S/N, Tabuleiro do Martins, Maceió - AL, Cep: 57072-970.

\section{Ana Cristina Brito Arcoverde}

ana.arcoverde@gmail.com

Universidade Federal de Pernambuco (UFPE)

Doutora em Sociologia na área de Estudos das Sociedades Latino-Americanas pela Universidade de Paris III, La Sorbonne Nouvelle, França.

Professora do Departamento e Pós-graduação em Serviço Social da Universidade Federal de Pernambuco (UFPE).

UFPE - Centro de Ciências Sociais Aplicadas

Av. dos Economistas, s/n, sala C, 23, 1 andar

Cidade universitária

Recife - Pernambuco - Brasil

CEP: 50670-901 